\title{
The physiology of the hunted deer
}

Georgia Mason

n the summer of 1997 one of Britain's largest landowners, the National Trust, banned the hunting of deer with hounds on its land. The decision, which caused a wave of protest from hunt-supporters, was based on a two-year study by Patrick Bateson and Elizabeth Bradshaw of how hunting affects the biology of red deer.

Late last month, the physiological data from the study were published ${ }^{1}$, allowing scrutiny of the science behind the debate. They show that the effects of extended pursuits are severe - disruption of muscle tissue, the exhaustion of glycogen reserves, maximally high levels of cortisol and the breakdown of red blood cells. That being hunted with dogs causes stress is scarcely surprising. But these data reveal just how poorly adapted red deer are to predation by sustained pursuit; they also come at a time when moves to outlaw fox-hunting throughout Britain are gathering momentum.

Few would argue against the view that red deer populations need managing. But culling deer by hunting them with hounds, the hunters sometimes being mounted, sometimes on foot, is highly controversial (the deer are chased, and when captured are shot). Bateson's remit was to evaluate scientifically the suffering this causes ${ }^{2}$. But what data can be used to address the question? Strictly speaking, the 'other minds' problem makes it impossible to tell the feelings of another animal, even a fellow human being ${ }^{3}$. But human emotions are usually accompanied by changes in behaviour and physiology - raised heart rates, sweaty palms, wincing, and so on - and it is this sort of correlate that allows inferences about the mental states of other species to be made ${ }^{4}$.

In practical terms, two complementary approaches are taken. One is to compare the behaviour and physiology of the animals under study with animals exposed to hunger, electric shocks, illness, injury and the like experiences that are assumed to be unpleasant or already deemed unacceptable by society.

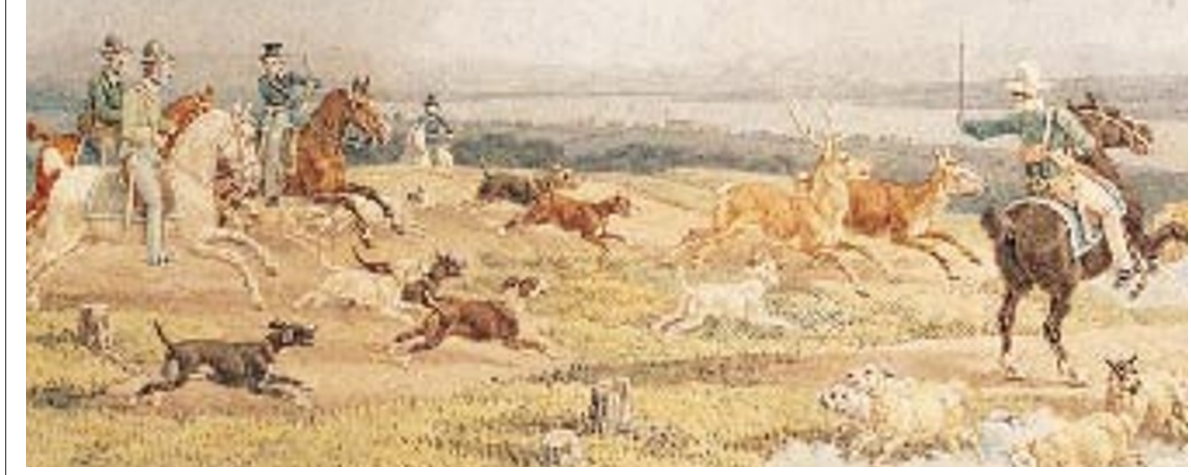

Figure 1 Hounded — a stag hunt (1839) painted by W. A. Kobell.

The other is to use the biological changes that occur in humans feeling fear, anxiety or pain, and to look for them in animals. Such changes include depressed immunity, gastric ulceration and altered functioning of the hypothalamus-pituitary-adrenal system, which is responsible for secreting corticosteroid hormones (cortisol, for example).

Bateson and Bradshaw ${ }^{1}$ collected blood and muscle samples from 64 deer hunted over the course of a year. They also sampled 50 deer that had been stalked and cleanly shot with rifles. And in a part of the study not published here, they examined eight seriously injured deer which had, for instance, been hit by cars ${ }^{2}$. These provided cases of suffering deemed 'unacceptable', because deer found in this state are generally euthanized as quickly as possible.

The physiological differences between hunted deer and those that were simply shot proved to be enormous. Not surprisingly, one difference was in the mobilization of fuel needed for physical exercise. For example, all hunted deer showed a rise in plasma glucose, followed by a fall to below baseline levels as stored carbohydrates were depleted. Muscle samples further revealed the extent of carbohydrate depletion: acidity levels declined the longer the hunt had gone on, showing that glycogen (which after death is converted to lactic $\operatorname{acid}^{5}$ ) had similarly declined. Indeed, in leg muscles, asymptotic levels of alkalinity were reached in any hunt that lasted longer than three hours.

From these data, the authors argue that, in at least a quarter of hunts that lead to a kill, carbohydrate reserves are at an absolute minimum, and that this is responsible for the animals' state of seeming exhaustion when they are captured. Hunted deer also had levels of cortisol 70 times those of shot animals, along with tenfold increases in both haem, the pigment released by damaged red blood cells, and two enzymes ordinarily at high levels only in striated muscle: creatine kinase and a form of lactate dehydrogenase.
So what does all this reveal about welfare? The interpretation of high cortisol concentrations, which are commonly taken to indicate stress, is complicated by the hormone's biological function (promotion of fuel mobilization when large amounts are need$\left.\mathrm{ed}^{4}\right)$. But cortisol release during exercise is rarely maximal unless psychological stress is also involved ${ }^{6}$. The values reported here resemble the maximum seen in studies of the response of red deer to experimental administration of adrenocorticotrophic hormone. They are also higher than those seen in deer being transported by lorry for slaughter at abattoirs $^{7,8}$, and similar to those in the badly injured deer ${ }^{2}$.

The release of creatine kinase from leaky myofibrils is common in humans doing physical exercise, but high levels can be taken to be a manifestation of actual pathology. In this study, 6.6 per cent of the deer had kinase levels greater than those indicating muscle damage in exercising horses ${ }^{9}$. High levels of this and lactate dehydrogenase are also symptomatic of a state called 'capture myopathy', in which acutely stressed animals become reluctant to move, hyperthermic and may die $\mathrm{e}^{10,11}$. Bateson and Bradshaw did not find the extreme acidosis often reported for wild ungulates (zebra and wildebeest, for example) which die after capture ${ }^{11}$. But from the high levels of myofibril enzyme leakage, and the escape of haem from red blood cells (which might reflect hyperthermia), and from studies of white-tailed deer ${ }^{12}$, the authors argue that some 8 per cent of red deer that escape the hunt may later die $\mathrm{di}^{1,2}$.

Apart from what it tells us about hunted deer, Bateson and Bradshaw's paper provides a model for investigations into the welfare consequences of other traditional British country sports, such as fox-hunting and hare-coursing (and, more internationally, big-game fishing, bull-fighting and bull-running). The stress physiology of any scientist bold enough to enter these highly emotional and political arenas would also make for a revealing study.

Georgia Mason is in the Department of Zoology,

University of Oxford, South Parks Road, Oxford

OX1 3PS, UK.

\footnotetext{
Bateson, P. \& Bradshaw, E. L. Proc. R. Soc. Lond. B 264, 1-8 (1997)

2. Bateson, P. The Behavioural and Physiological Effects of Culling Red Deer (National Trust, London, 1997).

. Warburton, N. Philosophy - The Basics (Routledge, London, 1992).

4. Mason, G. J. \& Mendl, M. T. Anim. Welf. 2, 301-320 (1993)

5. Warriss, P. D., Bevis, E. A. \& Ekins, P. J. Br. Vet. J. 145, 378-383 (1989).

6. Mason, J. W. J. Psychiat. Res. 8, 323-333 (1971).

7. Goddard, P. J. et al. Can. J. Zool. 72, 1872-1880 (1994).

8. Carragher, J. F., Ingram, J. R. \& Matthews, L. R. Appl. Anim. Behav. Sci. 51, 143-158 (1997).

9. Volfinger, L., Lassourd, V., Michaux, J. M., Braun, J. P. \& Toutain, P. L. Am J. Physiol. 266, R434-R441 (1994).

10. McAllum, H. J. F. R. Soc. N. Z. Bull. 22, 65-72 (1985)

11. Harthoorn, A. M., Van der Walt, K. \& Young, E. Nature 247, 577 (1974).

12. Beringer, J., Hansen, L. P., Wilding, W., Fischer, J. \& Schiff, S. L. J. Wildl. Mgmt 60, 373-380 (1996).
} 